\title{
Risk Assessment Education: Utilizing Interactive Video for Teaching Health and Safety
}

\author{
Joseph Price, Gary Wills \\ Electronics and Computer \\ Science \\ University of Southampton, \\ Southampton, UK \\ $\{j t p, g b w\} @ e c s . s o t o n . a c . u k$
}

\author{
Itiel E. Dror \\ Psychology \\ University of Southampton, \\ Southampton, UK \\ id@ecs.soton.ac.uk
}

\author{
Tom Cherrett, Sarah Maynard \\ Civil Engineering \\ University of Southampton, \\ Southampton, UK \\ $\{t j c 3, \operatorname{sjm}\} @$ soton.ac.uk
}

\begin{abstract}
Work related accidents in the construction industry are at an unacceptably high level. Better education (particularly related to re-training) across all skill levels in the industry is seen as an integral part of any solution. Traditional lecture-based courses often fail to re-create the dynamic realities of managing health and safety (H\&S) on-site. They therefore do not sufficiently engage the students in deeper learning (which results in remembering and using what was learned). Interactive video appears to be one method which can aid this process by better engaging students with the material. This paper describes the development of an interactive video used to teach students about risks in setting out on-street traffic engineering experiments.
\end{abstract}

\section{$1 \quad$ Introduction}

The cost of health and safety failures to UK industry is currently estimated at up to $£ 6.5$ billion per annum [3]. Research specifically on the construction sector has suggested that uninsured losses from accidents (whether resulting in personal injury or not) can cost anything between 8 and 36 times the insured sum, in many cases making the difference between profit and loss [1]. In 2000, the UK Government set out specific national targets for improving Health and Safety in the workplace. The number of working days lost per 100,000 workers from work-related injury and ill health are to be reduced by $30 \%$ by 2010 and the incidences of fatal and major injuries by $10 \%$.

It is now considered however, that health and safety in education should be presented 'as an intellectual challenge illustrated by practical example' [2] and that Higher Education institutions must instill in students a sound knowledge of their legal responsibilities, of risk and the principles of risk management.

The need to develop more effective H\&S teaching mechanisms is not just confined to the construction industry. All students undertaking activities subject to risk assessment (field trips, laboratory experiments and lone working) could benefit from a more studentcentered interactive approach. The difficulty is often finding a place to effectively do this in an overcrowded curriculum and in a way that situates the material and engages the learner. Interactive video is one way in which this may be achieved.

This paper will explore the use of interactive video in teaching to enhance deeper learning and its potential application to the teaching area of risk assessment. The work carried to deliver such a system is described and the lessons learnt whilst implementing it discussed. The paper concludes with a discussion and direction for future work.

\section{$2 \quad$ Interactive video as a tool to aid deeper learning}

Interactive video can be defined as, "the use of computer systems to allow proactive and random access to video content based on queries or search targets" [7] .It eliminates the linearity associated with traditional video through the use of on screen controls (e.g. skip screen, pause video) which provide the learner with complete control of their learning experience and the speed with which they learn [7]. The interaction between the player and the video enhances engagement and curiosity, which are important factors in stimulating the learning process [1]. This can be further enhanced through the use of computer simulation, educational games, quizzes/exercises, case studies and the provision of timely feedback on performance as part of the learning experience. The use of interactive video to enable learning through the process of experiencing failure [4] has great potential for fostering 'deeper learning' and thus. enabling more effective application of principles learned in the workplace, accelerating the process of skill acquisition [5]. 


\section{$3 \quad$ Making the Risk Assessment Video}

The aim of this project was to produce a video for undergraduate/postgraduate engineering students showing the risks associated with filming traffic on a busy urban road. The video was filmed from the perspective of how not to undertake the fieldwork and was based on a well practiced technique that had been employed for registration plate capture surveys over a number of years.

\section{Scene 1: Dropping off equipment on-site}

Camera set up on the pavement just South of Beechmount Road. Over view looking North up the pavement showing South bound traffic and the joint pedestrian/cycle lane sign on a post.

\begin{tabular}{|l|ll|}
\hline \multicolumn{1}{|c|}{ Activity } & \multicolumn{1}{c|}{ Risks to Identify } \\
\hline - $\quad \begin{array}{l}\text { Van pulls up on A33 with } \\
\text { hazards on }\end{array}$ & - $\begin{array}{l}\text { Should not stop on the road. } \\
\text { Use a side road and carry } \\
\text { the equipment round }\end{array}$ \\
- $\begin{array}{l}\text { Man gets out of passenger } \\
\text { side wearing shorts, } \\
\text { sandals (no socks), tee-shirt } \\
\text { Opens side door and lifts } \\
\text { out camera case, tripod, car } \\
\text { battery, bag with leads in, } \\
\text { deck chair }\end{array}$ & - $\begin{array}{l}\text { No yellow jacket, no safety } \\
\text { shoes, no gloves for battery }\end{array}$ \\
$\begin{array}{l}\text { Shuts doors and van drives } \\
\text { off leaving man on the } \\
\text { pavement with equipment }\end{array}$ & In correct lifting of heavy \\
\hline
\end{tabular}

Figure 1 Extract from the filming scene plan.

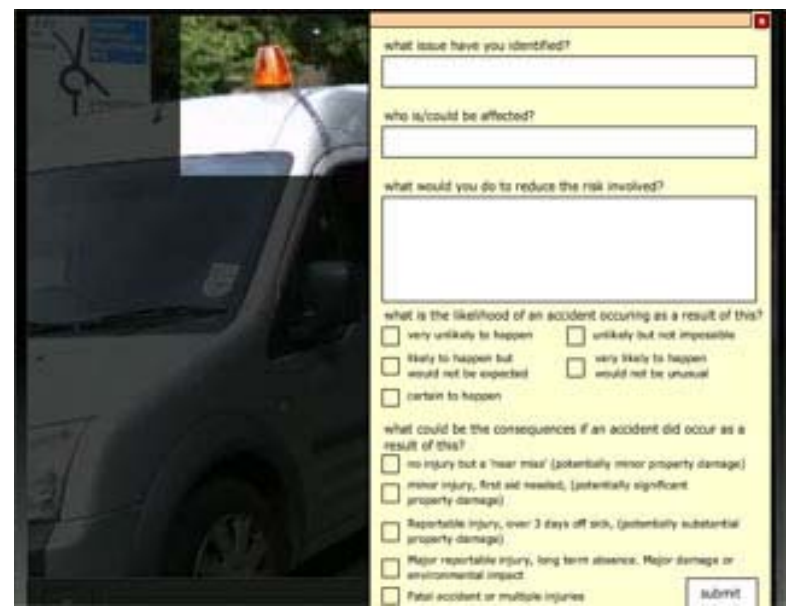

Figure 2 interactive video screen shot - clicking on a hazard

The video was designed to operate in three distinct stages and is played by the student through a web browser. It can be re-wound at any point until the end is reached:
1) The video is watched and hazards are identified by clicking on locations in the video and using a combination of free text boxes and statement declarations (Figure 2). It is possible to know at what exact time the student clicked the left mouse button and also the $\mathrm{x}$ and $\mathrm{y}$ position of the mouse pointer. Once finished this information is submitted to a database along with the student's name.

2) Once the interactive element of the video has been completed, the official hazards are then shown. A still image of each hazard is chronologically displayed accompanied by text explaining the hazard along with a still image illustrating the solution (Figure 3). The student can then navigate between hazards by using the 'next' and 'previous' buttons.

3) The video is viewed again as in 1) however this time each hazard is identified for the student as the video plays. Upon completion of filming, the subsequent video was imported into the Adobe Flash authoring environment.

The experiment set-up was filmed in one continuous take lasting just over two minutes.

The video scenes were meticulously planned (Figure 1) and the real on-street hazards minimized during the filming by having 'off-camera' personnel dealing with scene set up and operation. Camera positioning, hazard identification, incorrect and correct equipment set-up was all planned in set 'scene' sequences.

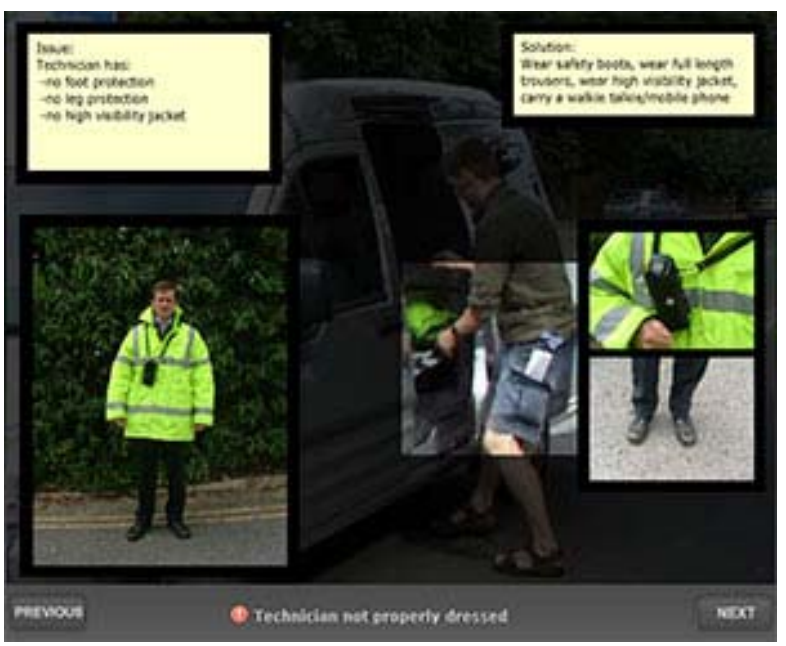

Figure 3 still image illustrating solution to hazard with accompanying text

After the video has been viewed once in its entirety, a basic calculation (unknown to the student) is carried 
out comparing the number of hazards identified against the actual number present. If there is a disparity the system suggests that the student re-examine the video and either look again for more hazards or look again at the hazards already identified. Upon reaching the end of the video a second time the interactive element of the video finishes and all hazard information along with the student's name is sent through the web browser via the HTTP POST protocol to a MySQL database.

The course instructor can view all submitted data using the administration panel and by clicking on a hazard identified by a student, the video will jump to the appropriate time and show where the student clicked.

\section{$4 \quad$ Discussion and Conclusion}

The case study video is currently being piloted and a first stage evaluation has been completed using a group of 75 second year undergraduate civil engineering students. This evaluation is aimed at identifying operational issues in using the video and gaining initial feedback on its usability and scope for aiding a current lecture series on risk assessment in construction management. The case study video was designed to complement a current lecture on risk assessment which used the traffic engineering experiment to engage students and test their lateral thinking related to risk identification and mitigation. $95 \%$ of the students stated that the lecture and video combined were an effective combination of learning tools for new students. $75 \%$ stated that the interactive video had enhanced their learning experience and $60 \%$ felt that more health and safety material on the module should be taught with the aid of this technique.

A key question concerning current $\mathrm{H} \& \mathrm{~S}$ material delivery is whether the basic recall of lecture notes in an exam environment (e.g. for NEBOSH or undergraduate degrees), or the recognition of answers in a multiple choice setting (CSCS test) is preparing individuals to execute, apply and prioritize matters of $\mathrm{H} \& \mathrm{~S}$ in the field. With the emphasis on 'multi-skilling' and continual professional development interactive video could be used to empower learners from across the spectrum (professionals seeking refresher courses to unskilled labourers preparing for CSCS) from a place and at a time best suited to their needs. Such tools could be used to teach both 'hard skills' (e.g. site emergency evacuation procedures) and 'soft skills' involving human interaction (e.g. decision-making under time pressure, communication, motivation and leadership). It is critical to develop such learning technologies in a way that takes into account (and harnesses) the cognitive mechanisms underlying learning and memory [8]. With the need to improve the teaching of $H \& S$ in education we believe that the use of interactive video will foster the deeper learning required.

It is envisaged that this project will be the start of a programme to provide interactive H\&S training for construction site workers. This could lead to a 'European Health and Safety Construction Skills License' in the same vein as the European Computer Driving License that is recognized across Europe. It could also create spin-offs in many other industry sectors that are bound by H\&S legislation. Future work will involve integrating work from the ASDEL project, to deliver a range of interoperable e-assessments [6].

\section{References}

1. DiPaola, S., \& Akai, C. (2006). Designing an adaptive multimedia interactive to support shared learning experiences. International Conference on Computer Graphics and Interactive Techniques ACM SIGGRAPH Educators program

2. HSE (2004) Identification and management of risk in undergraduate construction courses' (Supplementary report, April 2004) prepared by the Symonds Group Ltd, Liverpool John Moores University, Charlton Smith Partnership. Research Report 275

3. HSE (2006) The costs of accidents and ill health at work. Available at http://www.hse.gov.uk/costs/costs overview/cost s overview.asp, Accessed 15/4/06

4. Schank (1997) Virtual learning: a revolutionary approach to building a highly skilled workforce. McGraw-Hill.

5. Schwan, S., and Riempp, R. (2004). The cognitive benefits of interactive videos: learning to tie nautical knots. Learning and Instruction, 14 pp 293-305

6. Wills, G., Davis, H., Gilbert, L., Hare, J., Howard, Y., Jeyes, S., Millard, D. and Sherratt, R. (2007) Delivery of QTIV2 Question Types. In: International CAA Conference, 10th - 11th July 2007., Loughborough uk.

7. Zhang, D., Zhou, L., Briggs, R., and Nunamaker, J. (2006). Instructional video in e-learning: Assessing the impact of interactive video on learning effectiveness. Information and Management. (43), pp 15-27.

8. Dror, I. E., Stevenage, S. V., \& Ashworth, A. (2008). Helping the cognitive system learn: Exaggerating distinctiveness and uniqueness. Applied Cognitive Psychology. 